\title{
Análise econômica da produção de Acacia mearnsii De Wild e carvão vegetal no Vale do Caí e Taquari, Rio Grande do Sul
}

\author{
Economic analysis of Acacia mearnsii De Wild production and \\ charcoal in the Valley of Caí and Taquari, Rio Grande do Sul, Brazil
}

Flávio Cunha Laureano da Silva ${ }^{I}$ Jorge Antonio de Farias ${ }^{I I}$

\section{RESUMO}

O estudo objetivou analisar a viabilidade econômica da produção de acácia-negra e carvão vegetal em Brochier Maratá, Paverama e Poço das Antas. Os subsidios foram obtidos com aplicação de questionários in loco. Os critérios econômicos utilizados foram: Valor Presente Líquido (VPL), Valor Presente Líquido Infinito (VPL inf.). Valor Anual Equivalente (VAE), Valor Esperado da Terra (VET), Relação Benefício Custo (B/C), Taxa Interna de Retorno (TIR) e Custo Médio de Produção (CMPr). A taxa média de atratividade utilizada foi de $6,8 \%$ a.a. Os dados de produção de madeira foram oriundos de SCHNEIDER et al. (2000). Assim, o plantio de acácia-negra consorciada com milho mostrou-se viável, apresentando maior atratividade no Índice de Sitio 18: VPL de R\$ 2529,22 ha $a^{-1}$, VET de R\$ 384,91 ha $a^{-1}$, VPL infinito de R\$506,37 ha-1, TIR de 18,91\% e CMPr de R\$36,44 $\mathrm{m}^{-3}$. A produção de carvão vegetal mostrou-se mais viável nos fornos Brochier (CMPr de R\$ 0,32 $\mathrm{m}^{-3}$ e B/C de 1,94).

Palavras-chave: viabilidade, silvicultura, carbonização.

\section{ABSTRACT}

The study aimed to analyze the feasibility and the economic production of black wattle and charcoal in Brochier Maratá, Paverama and Poço das Antas Rio Grande do Sul, Brazil. Subsidies were obtained with in loco questionnaires. The economic criteria used were: Net Present Value (NPV), Infinite Net Present Value (NPV inf.), Annual Equivalent Value (VAE), Expected Value of Earth (VET), Benefit Cost Ratio $(B / C)$, internal rate of return (IRR) and average cost of production (CMPr). The average rate of attractiveness used was $6.8 \%$ p.a. The wood production data obtained was from SCHNEIDER et al. (2000). Thus, planting black acacia intercropped with maize proved to be viable, showing greater attractiveness in the 18 place index: NPV of $R \$ 2529,22 \mathrm{ha}^{-1}$ VET of $R \$ 384.91 \mathrm{ha}^{-1}$, VPL inf. of $R \$ 506.37 \mathrm{ha}^{-1}$, $T I R$ of $18.91 \%$ and CMPr of $R \$ 36.44 \mathrm{~m}^{-3}$. Charcoal production proved to be more feasible in the ovens Brochier (CMPr of $R \$ 0,32$ $m^{-3}$ and $B / C$ of 1,94$)$.

Key words: viability, forestry, carbonization.

\section{INTRODUÇÃO}

$\mathrm{O}$ rápido crescimento da acácia-negra, associado ao aproveitamento integral da madeira, torna essa espécie ideal para reflorestamento e utilização industrial. A casca é utilizada para extração do tanino e a madeira como lenha, fabricação de papel e celulose e carvão vegetal (SANTOS et al., 2001). O maciço florestal da espécie no estado, segundo ABRAF (2007), é de 152,5 mil hectares.

Segundo SABLOWSKI (2008), o uso desse tipo de biomassa como fonte energética traduzse como uma prática sustentável, capaz de promover geração de emprego e renda. Diante da importância socioeconômica dessas atividades, objetivou-se analisar a viabilidade econômica da produção de acácia-negra e carvão vegetal no Vale do Caí e Taquari.

\section{MATERIAL E MÉTODOS}

A região de estudo abrangeu os municípios de Brochier, Maratá, Paverama e Poço das Antas, pertencentes à encosta inferior do nordeste (MOMBACH et al., 2005). O clima da área de estudo, segundo ROSSATO (2011), é subtropical III úmido com chuvas anuais entre $1700-1800 \mathrm{~mm}$ e temperatura média entre $17^{\circ}-20^{\circ} \mathrm{C}$.

Os subsídios para o processamento dos dados foram obtidos através da aplicação de questionários in loco. Os critérios utilizados na análise econômica estão dispostos na tabela 1 .

A razão Benefício-Custo $(\mathrm{B} / \mathrm{C})$ estabelece a relação entre o valor atual das receitas e o valor atual dos custos (VITALE\& MIRANDA, 2010).

\footnotetext{
'Programa de Pós-graduação em Engenharia Florestal, Centro de Ciências Rurais (CCR), Universidade Federal de Santa Maria (UFSM), Av. Roraima, 1000, 97105-900, Santa Maria, RS, Brasil. E-mail: flaviolauerano@hotmail.com. Autor para correspondência.

IDepartamento de Ciências Florestais, CCR, UFSM, Santa Maria, RS, Brasil.
} 
Tabela 1- Critérios de análise econômica.

\begin{tabular}{|c|c|c|}
\hline Critério & 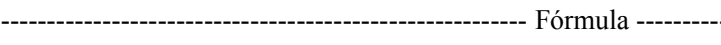 & 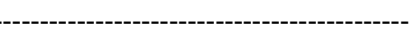 \\
\hline $\begin{array}{l}\text { Valor } \\
\text { Presente } \\
\text { Líquido }\end{array}$ & $V P L=\sum_{j=0}^{n} R_{j}(1+i)^{-j}-\sum_{j=0}^{n} C j(1+i)^{-j}$ & $\begin{array}{l}C_{j}=\text { custo no final do ano } j \\
R_{j}=\text { receita no final do ano } j \\
i=\text { taxa de desconto } \\
n=\text { duração do projeto em anos }\end{array}$ \\
\hline Taxa Interna de Retorno & $+i)^{-j}-\sum_{j=0}^{n} C_{j}(1+i)^{-j}=0$ & $\begin{array}{l}\mathrm{Rj}=\text { receita no final do ano } \mathrm{j} \\
\mathrm{Cj}=\text { custo no final do ano } \mathrm{j} \\
\mathrm{n}=\text { duração do projeto em anos } \\
\mathrm{i}=\text { taxa de desconto. }\end{array}$ \\
\hline $\begin{array}{l}\text { Relação Benefício } \\
\text { Custo }\end{array}$ & $\mathrm{R}_{(\mathrm{i})}=\frac{V \mathrm{~B}_{(\mathrm{i})}}{V \mathrm{C}_{(\mathrm{i})}}$ & $\begin{array}{l}\mathrm{VB}_{(\mathrm{i})}=\text { valor presente à taxa i da } \\
\text { sequência de benefícios } \\
\mathrm{VC}_{(\mathrm{i})}=\text { valor presente à taxa i da } \\
\text { sucessão de custos }\end{array}$ \\
\hline Custo Médio de Produção & $\operatorname{CMPr}=\frac{\sum_{j 0}^{\mathrm{n}} \mathrm{CT}_{\mathrm{j}}}{\sum_{\mathrm{j}=0}^{\mathrm{n}} \mathrm{QT}_{\mathrm{j}}}$ & $\begin{array}{l}\mathrm{CT}_{\mathrm{j}}=\text { custo total atualizado } \\
\mathrm{QT}_{\mathrm{j}}=\text { produção total equivalente }\end{array}$ \\
\hline Valor Anual Equivalente & $\mathrm{VAE}=\frac{\mathrm{VPL}\left[(1+\mathrm{i})^{\mathrm{t}}-1\right](1+\mathrm{i})^{\mathrm{nt}}}{(1+\mathrm{i})^{\mathrm{nt}}-1}$ & $\begin{array}{l}\text { VPL }=\text { Valor Presente Líquido } \\
\mathrm{i}=\text { taxa de desconto } \\
\mathrm{n}=\text { duração do projeto } \\
\mathrm{t}=\text { número de períodos }\end{array}$ \\
\hline Valor Presente Líquido Infinito & $\mathrm{VPL}_{\infty}=\frac{\operatorname{VPL}(1+\mathrm{i})^{\mathrm{n}}}{(1+\mathrm{i})^{\mathrm{n}}-1}$ & $\begin{array}{l}\text { VPL = Valor Presente Líquido } \\
\mathrm{i}=\text { taxa de desconto } \\
\mathrm{n}=\text { duração do projeto }\end{array}$ \\
\hline Valor Esperado da Terra & $V E T=\frac{V_{o} R L(1+i)^{n}}{(1+i)^{n}-1}$ & $\begin{array}{l}\mathrm{V}_{0} \mathrm{RL}=\text { valor atual da receita } \\
\text { líquida que se repete a cada ciclo; } \\
\text { os demais termos são conforme } \\
\text { definidos. }\end{array}$ \\
\hline
\end{tabular}

O Custo Médio de Produção (CMPr) é a relação entre o custo total atualizado e a produção total equivalente, sendo utilizado quando se deseja operar com o custo médio mínimo, independente da quantidade produzida e do tempo de duração do investimento (REZENDE \& OLIVEIRA, 2011).

O Valor Presente Líquido (VPL), de acordo com SILVA \& FONTES (2005), é a diferença entre o valor presente das receitas e o valor presente dos custos. Esse critério também pode ser calculado considerando a replicação do projeto para um horizonte infinito (VPL infinito)

O Valor Anual Equivalente (VAE) é definido como a parcela periódica e constante do VPL, ou seja, transforma o valor atual do projeto (VPL) em fluxo de receitas e custos periódicos e contínuos, durante a vida útil do projeto (SILVA \& FONTES, 2005).

A Taxa Interna de Retorno (TIR) é a taxa que gera um VPL igual a zero, ou seja, faz com que os valores presentes de custos e receitas se igualem (TORRES et al., 2000).

O Valor Esperado da Terra (VET) é um termo florestal usado para representar o valor presente líquido de uma área de terra nua a ser utilizada para a produção de madeira, calculado com base numa série infinita de rotações (SILVA \& FONTES 2005).

A taxa média de atratividade utilizada foi de $6,8 \%$ a.a., valor proposto de remuneração da poupança no histórico do Banco Central para o mês de dezembro de 2012.

Alguns custos fixos (equipamentos, máquinas, benfeitorias) foram submetidos ao cálculo de depreciação linear ao longo do período, calculado da seguinte forma (TIMOFEICZYK JÚNIOR, 2004):

$$
\mathrm{De}=\frac{(\mathrm{Va}-\mathrm{Vr})}{\mathrm{Vu}}
$$

Em que:

$\mathrm{De}=$ Depreciação (R\$ano); 
$\mathrm{Va}=$ Valor da aquisição $(\mathrm{R} \$)$;

$\mathrm{Vr}=$ Valor residual $(\mathrm{R} \$)(\mathrm{Va} * \mathrm{~d})$;

$\mathrm{d}=$ taxa anual de depreciação;

$\mathrm{Vu}=$ vida útil (anos).

A taxa de depreciação (d) e a vida útil $\mathrm{Vu}$ ) desses itens foram coletadas na Instrução Normativa da Secretaria da Receita Federal no162 de 31 de dezembro de 1998. Na análise de plantios de acácia, os dados de produção de madeira por hectare utilizados foram oriundos de SCHNEIDER et al. (2000) para os índices de sítio 12,14,16 e 18.

$\mathrm{O}$ índice de sítio, na área florestal, tem sido o método mais prático e difundido para classificação da produtividade, uma vez que utiliza a variável altura dominante, por ser correlacionada com a produção volumétrica sem sofrer influência significativa, quando comparado com outras variáveis da árvore, dos tratamentos silviculturais e da competição entre espécies (TONINI et al., 2001).

\section{RESULTADOS}

O plantio de acácia-negra com rotação de nove anos, espaçamento inicial 2,0x1,5 metros, consorciado com milho, no primeiro ano, possui os custos dispostos na tabela 2 .

Tabela 2 - Custos do consórcio de acácia-negra e milho.

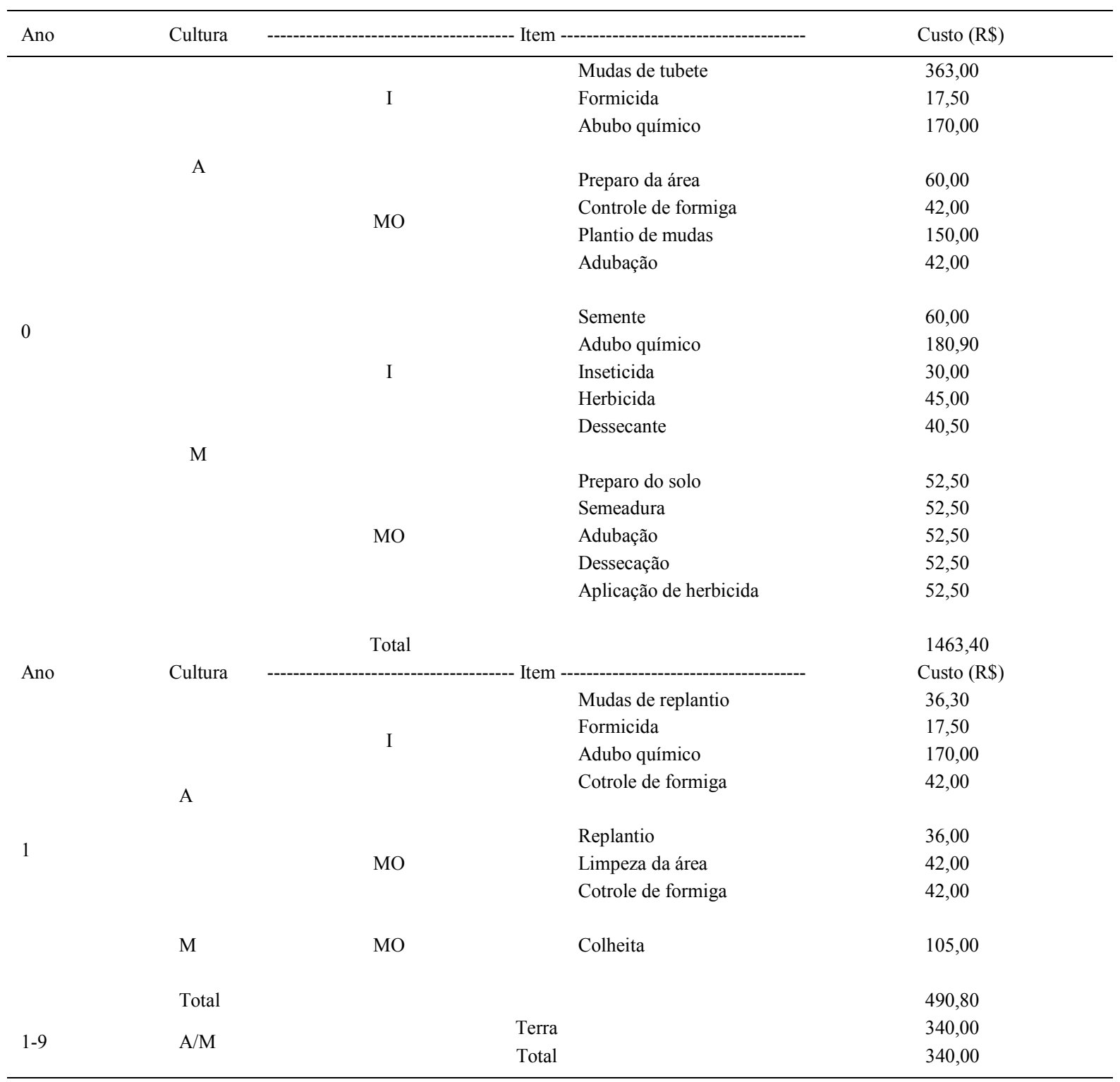

Em que: $\mathrm{A}=$ acácia-negra; $\mathrm{M}=$ milho; $\mathrm{I}=$ insumo; $\mathrm{MO}=$ mão-de-obra.

Ciência Rural, v.45, n.5, mai, 2015. 
No ano de implantação do projeto $57,7 \%$ dos custos (insumos e mão de obra) foram oriundos da acácia-negra e $42,3 \%$ do milho, totalizando $\mathrm{R} \$ 1463,40$ $\mathrm{ha}^{-1}$. No ano seguinte, $78,6 \%$ dos custos foram despendidos em atividades de manutenção e insumos necessários para acácia-negra e 21,4\% necessários para a colheita do milho. O custo de oportunidade da terra, como no cenário anterior, foi de $\mathrm{R} \$ 340,00 \mathrm{ha}^{-1}$.

O custo de colheita na região é cobrado por metro cúbico de madeira, diferindo-se então em cada índice de sítio (Tabela 3). O preço pago pela madeira de acácia-negra cortada e empilhada encontrado foi de R\$ $58,00 \mathrm{~m}^{-3} \mathrm{e}$ o custo de colheita empilhada de $\mathrm{R} \$ 21,00 \mathrm{~m}^{-3}$.

Considerou-se a produção de milho no ano 01 de 45 sacos por hectare, com valor de venda de R $\$$ 26,50 a unidade. Vale ressaltar que os custos, receitas e produção do milho foram calculados com base em $75 \%$ da área, devido ao consórcio com a acácia.

Os valores dos critérios relataram a viabilidade econômica da atividade (Tabela 4). Os valores de VPL foram positivos, ou seja, quando descapitalizados, as receitas superaram os custos. Esse critério, quando considerado um horizonte infinito, também apresentou valores positivos, ou seja, atrativos.

Quando consideradas as parcelas anuais, os valores também foram positivos (VAE). A taxa interna de retorno mostrou-se maior que a taxa proposta, ou seja, para que o VPL fosse zero nos cenários, a taxa média de atratividade deveria ser maior. O VET, o valor máximo que poderia ser pago por unidade de área, foi maior que o valor pago, ou seja, a capacidade de produção da terra gerou valores mais atrativos que o comercializado na região.

$\mathrm{Na}$ variação dos valores de cada critério na dependência dos diferentes índices de sítio, puderamse observar valores mais atrativos com o aumento do índice de sítio (aumento da produção), já que os
Tabela 3 - Produção por índice de sítio e custo de colheita.

\begin{tabular}{lll}
\hline Índice de Sítio & Produção $\left(\mathrm{m}^{3}{ }_{\mathrm{cc}} \mathrm{ha}\right)$ & $\begin{array}{l}\text { Custo de colheita } \\
(\mathrm{R} \$ / \mathrm{ha})\end{array}$ \\
\hline 12 & 145,90 & $3.063,90$ \\
14 & 185,10 & $3.887,10$ \\
16 & 233,90 & $4.911,90$ \\
18 & 250,70 & $5.264,70$ \\
\hline
\end{tabular}

custos de implantação e manutenção são os mesmos e a receita gerada no final do período aumentou.

FLEIG (1993), em análise econômica de acácia-negra consorciada com milho, rotação de nove anos e taxa de $6,0 \%$ a.a., apresentou, em muitos casos,comportamento semelhante. Considerando o valor do dólar comercial de $\mathrm{R} \$ 2,33$, o autor apresentou os seguintes resultados: em sítio ruim, relatou valores de VPL de R -231,79 ha-1, VET de R\$ $-24,33$ ha $^{-1}$ e B/C de 0,89; em sítio médio, valores de VPL de R \$ 1422,139 ha ${ }^{-1}$, VET de R $\$ 4805,136$ e B/C de $1,59 \mathrm{ha}^{-1} ;$ e, em sítio bom, valores de VPL de R\$ 2996,194 ha ${ }^{-1}$, VET de R $\$ 9516,466$ ha $^{-1}$ e B/C de 2,08.

A produção anual de carvão vegetal em dois fornos com capacidade de cinco metros cúbicos possui custos e receitas diferentes, dependendo do tipo estrutura (Tabela 5).

$\mathrm{O}$ forno rabo-quente foi o que apresentou menores custos, devido à simplicidade de sua estrutura e menores receitas ( $\mathrm{R} \$ 36.054,80$ ), devido a sua produtividade $\left(900 \mathrm{~kg}\right.$ fornada $\left.{ }^{-1}\right)$

Esse tipo de forno também é encontrado com uma chaminé acoplada, que, além de facilitar o trabalho com a redução da fumaça liberada, aumenta a produtividade $\left(1100 \mathrm{~kg} \mathrm{ciclo}^{-1}\right)$, devido à maior concentração de calor no interior do forno e, consequentemente o rendimento.

O forno Brochier apresentou maiores custos, devido ao valor despendido para sua construção

Tabela 4 - Análise econômica da produção de acácia-negra consorciada com milho.

\begin{tabular}{|c|c|c|c|c|}
\hline \multirow{2}{*}{ Critério } & \multirow[b]{2}{*}{12} & \multirow[b]{2}{*}{14} & \multirow[b]{2}{*}{16} & \multirow[b]{2}{*}{18} \\
\hline & & & & \\
\hline Valor Presente Líquido (R $\$ /$ ha) & 411,01 & 1203,32 & 2182,66 & 2529,22 \\
\hline Valor anual equivalente ( $\mathrm{R} \$ /$ ha/ano) & 62,55 & 183,12 & 333,23 & 384,91 \\
\hline Valor Presente Líquido Infinito (R \$ha) & 919,83 & 2693,01 & 4900,44 & 506,37 \\
\hline Taxa Interna de Retorno (\%) & 9,46 & 13,64 & 17,71 & 18,91 \\
\hline Valor Esperado da Terra (R\$/ha) & 5919,83 & 7693,01 & 9900,44 & 10660,37 \\
\hline Custo Médio de Produção (R\$/m³) & 43,65 & 40,27 & 37,26 & 36,44 \\
\hline
\end{tabular}


Tabela 5 - Custos e receitas da produção de carvão vegetal por tipo de forno.

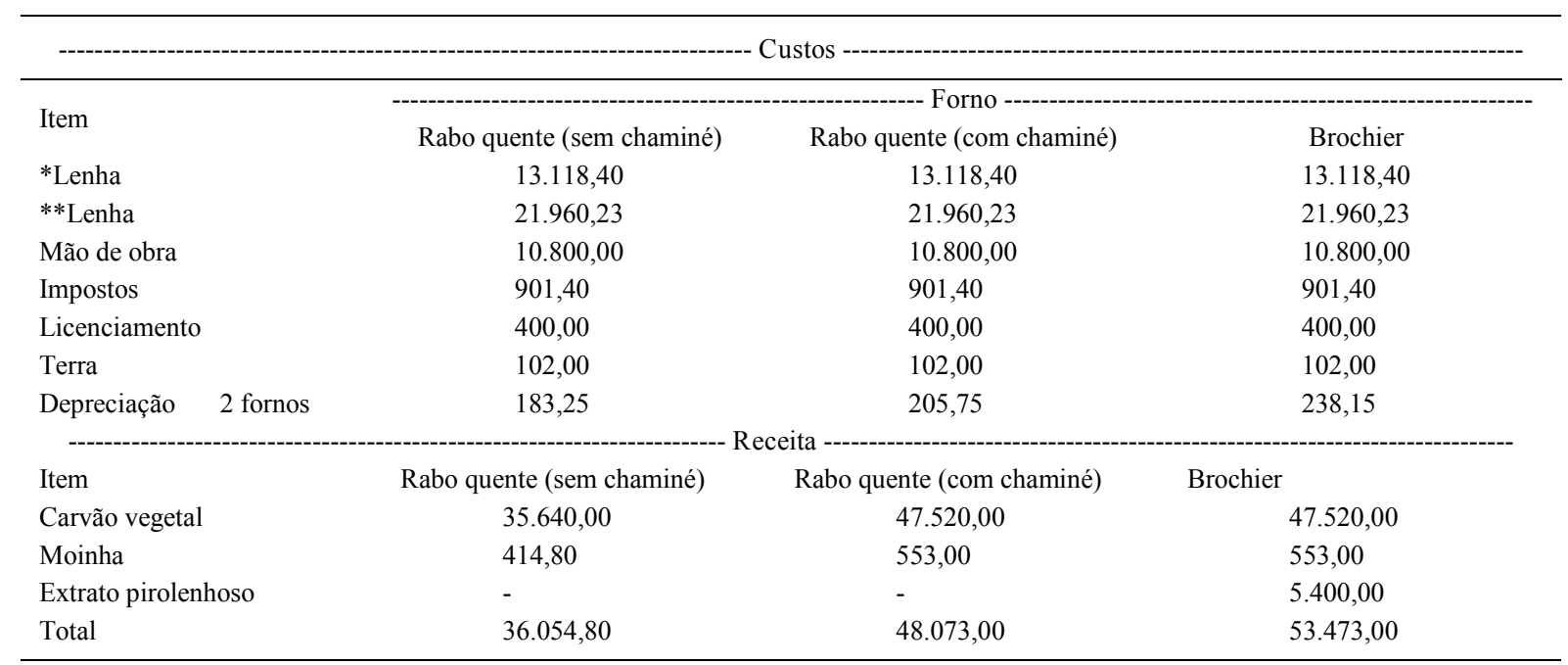

ser mais elevado. Além disso, apresentou maiores receitas $(\mathrm{R} \$ 53.473,00)$, devido à alta produtividade $\left(1100 \mathrm{~kg}\right.$ ciclo $\left.^{-1}\right)$ de carvão e subprodutos (extrato pirolenhoso e moinha).

Em todos os casos, o item com maior custo relatado foi a lenha, diferindo de valor quando comprada de terceiros ou produção própria. $\mathrm{O}$ custo da matéria-prima própria considerado foi o Custo Médio de Produção do índice de sítio 18 . O custo da lenha comprada $(\mathrm{R} \$ 61,00)$ é originário valor da matéria prima, acrescido de $\mathrm{R} \$ 3,00 \mathrm{~m}^{-3}$ despendido com transporte.

A produção de carvão mostrou-se viável economicamente (Tabela 6). O Custo Médio de Produção foi menor nos fornos rabo-quente com chaminé e Brochier, devido à maior produtividade desses fornos e à pouca diferença de custos na construção entre eles. Com isso, o produtor consegue arcar com os gastos despendidos e adquirir uma renda por quilo de carvão comercializado.

A Relação Benefício Custo apresentou valores com maior atratividade nos fornos Brochier, ou seja, para cada real gasto na produção de carvão vegetal nesse tipo de forno, há uma maior remuneração (receita) para o produtor. Isso se deve principalmente à maior renda oriunda da produção nesses fornos e, como no CMPr, pouca diferença de custos entre eles.

\section{CONCLUSÃO}

O plantio de acácia-negra consorciada com milho possui viabilidade econômica, apresentando valores mais atrativos quando maior a produção (Índice de Sítio 18): VPL de R\$2529,22 ha-1, VET de $384,91 \mathrm{ha}^{-1}$, VPL infinito de 506,37 ha' $\mathrm{ha}^{-1}$, TIR de $18,91 \%$ e CMPr de $36,44 \mathrm{~m}^{-3}$.

A produção de carvão vegetal nos fornos rabo-quente (com e sem chaminé) e Brochier também se mostrou viável. Os valores mais atrativos foram encontrados com a produção da própria madeira para carbonização, aliado à utilização do forno Brochier para o processo produtivo (CMPr de $\mathrm{R} \$ 0,32 \mathrm{~m}^{-3}$ e $\mathrm{B} / \mathrm{C}$ de 1,94 ).

Tabela 6 - Análise econômica da produção de carvão vegetal.

\begin{tabular}{|c|c|c|c|}
\hline Condição & 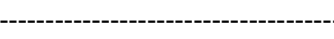 & -------- Lenha própria ---------. & - \\
\hline \multirow{2}{*}{ Critério } & \multicolumn{3}{|c|}{ 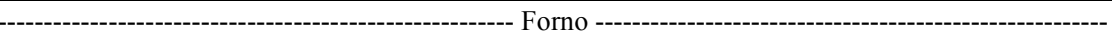 } \\
\hline & Rabo quente (sem chaminé) & Rabo quente (com chaminé) & Brochier \\
\hline Custo Médio de Produção (R\$/Kg) & 0,42 & 0,32 & 0,32 \\
\hline $\mathrm{B} / \mathrm{C}$ & 1,33 & 1,75 & 1,94 \\
\hline Condição & 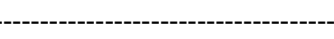 & ----- Lenha de terceiros ------. & ---------- \\
\hline \multirow{2}{*}{ Critério } & Rabo quente (sem chaminé) & Rabo quente (com chaminé) & Brochier \\
\hline & 01 & 02 & 03 \\
\hline Custo Médio de Produção (R\$/Kg) & 0,52 & 0,42 & 0,42 \\
\hline $\mathrm{B} / \mathrm{C}$ & 1,04 & 1,32 & 1,47 \\
\hline
\end{tabular}




\section{REFERÊNCIAS}

ASSOCIAÇÃO BRASILEIRA DE PRODUTORES DE FLORESTAS PLANTADAS. Anuário Estatístico da ABRAF: ano base 2006. Brasília, 2007.80p.

FLEIG, F.D. Análise econômica de sistema de produção com acácia-negra no Rio Grande do Sul. 1993. 62f . Dissertação (Mestrado em Engenharia Florestal - Programa de Pós-graduação em Engenharia Florestal, Universidade Federal de Santa Maria, RS.

MOMBACH, G.F. et al. O desenvolvimento territorial na microrregião de Salvador do Sul: Estudo de Caso de Turismo Rural. Revista Extensão Rural e Desenvolvimento Sustentável, Porto Alegre, v.1 n.4, nov/dez 2005.

REZENDE, J.L.; OLIVEIRA, A.D. Análise econômica e social de projetos florestais. Viçosa: UFV, 2011. 272p.

ROSSATO, M.S. Os climas do Rio Grande do Sul: variabilidade, tendências e tipologia. 2011. 240f. Tese (Doutorado em Geografia) Programa de Pós-Graduação em Geografia, Universidade Federal do Rio Grande do Sul, RS.

SABLOWSKI, A.R.M. Balanço de materiais na gestão ambiental da cadeia produtiva do carvão vegetal para a produção de ferro-gusa em Minas Gerais. 2008. 240f. Tese (Doutorado em Geografia). Programa de Pós Graduação em Ciências Florestais, Universidade de Brasília, DF.
SANTOS, A.F. et al. O complexo gomose da acácia-negra. Curitiba: Embrapa Colombo, 2001. 8p.(Circular técnica n.44).

SCHNEIDER, P.R. et al. Subsídios para o manejo da acácianegra, Acacia mearnsii De Wild. Santa Maria, RS: UFSM, Centro de Pesquisas Florestais, 2000. 71p.

SILVA, M. L.; FONTES, A. A. R. Discussão sobre os critérios de avaliação econômica: Valor Presente Líquido (VPL), Valor Anual Equivalente (VAE) e valor esperado da terra (vet). Revista Árvore, Viçosa, v.29, n.6, p.931-936, 2005. Disponível em: <http://www.scielo.br/scielo.php?pid=S0100$67622005000600012 \&$ script $=$ sci_arttext $>$. Acesso em: 26 mar. 2013. Doi:10.1590/S0100-67622005000600012.

TIMOFEICZYK, R. JR. Análise econômica do manejo de baixo impacto em florestas tropicais um estudo de caso. 2004. 14f. Tese (Doutorado em Engenharia Florestal - Programa de Pós-graduação em Engenharia Florestal, Universidade Federal do Paraná, PR.

TONINI, H. et al. Crescimento em altura de Pinus elliottii Engelm., na região de Piratini no Rio Grande do Sul, Brasil. Ciência Rural, Santa Maria, v.31, n.3, p.417-423, 2001. Disponível em: <http://www.scielo.br/scielo.php?pid=S010384782001000300008\&script $=$ sci arttext $>$. Acesso em: 27 mar. 2013. doi:10.1590/S0103-84782001000300008.

VITALE, V.; MIRANDA, G. de M. Análise comparativa da viabilidade econômica de plantios de Pinus taeda e Eucalyptus dunnii na região centro sul do Paraná. Revista Floresta, Curitiba, v.40, n.3, p.469-476, 2010. 